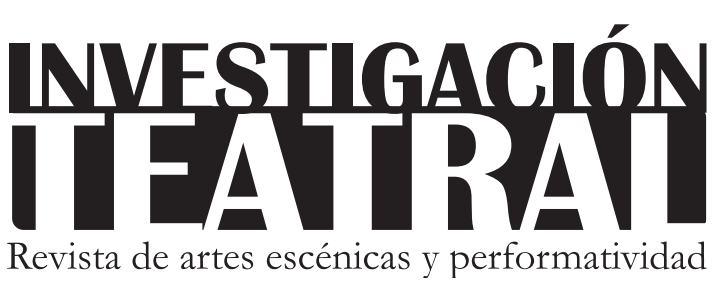

Vol. 9, Núm. 14

octubre 2018-marzo 2019

Segunda época

ISSN impreso: 1665-8728

ISSN electrónico: 2594-0953

Universidad Veracruzana

\title{
IN MEMORIAM: Félix Lozano
}

\author{
Luis Mario Moncada*
}

\footnotetext{
* Organización Teatral de la Universidad Veracruzana, México. e-mail: callejondurango@gmail.com
}

Recibido: 31 de agosto de 2018

Aceptado: 17 de septiembre de 2018 


\section{IN MEMORIAM: Félix Lozano}

\section{In memoriam del actor Félix Lozano Reyes (1959-2018)}

$\mathrm{F}$ élix Lozano fue uno de los actores más representativos de la Compañía Titular de Teatro de la Universidad Veracruzana, en la que trabajó durante 31 años (desde 1987), hasta su fallecimiento el 8 de mayo de 2018 en la ciudad de Xalapa, Veracruz. Era maestro en Filosofía, egresado de la Facultad de Teatro y de la Facultad de Arquitectura de la Universidad Veracruzana (UV). Fue escenógrafo e iluminador teatral, pero destacó por su labor como actor de cine y teatro, donde participó en más de sesenta obras de diversos temas y géneros. Sus últimas actuaciones con la Compañía de Teatro de la UV fueron, a partir de 2015: Beisbol, escrita y dirigida por David Gaitán; Psico/Embutidos de Richard Viqueira; Impro Big Band Xalapa, bajo la dirección de Omar Argentino; Crónicas veracruzanas, basada en textos de Fernanda Melchor; Las muertas, dirigida por Martín Acosta; El puro lugar, con dramaturgia de Jorge Vargas, Alejandro Flores y Luis Mario Moncada, y La extinta variedad del mundo, escrita y dirigida por Alberto Villarreal.

El siguiente texto fue leído por Luis Mario Moncada, director de la Compañía Titular de Teatro de la Universidad Veracruzana, durante el homenaje póstumo realizado en el mes de junio de 2018. 


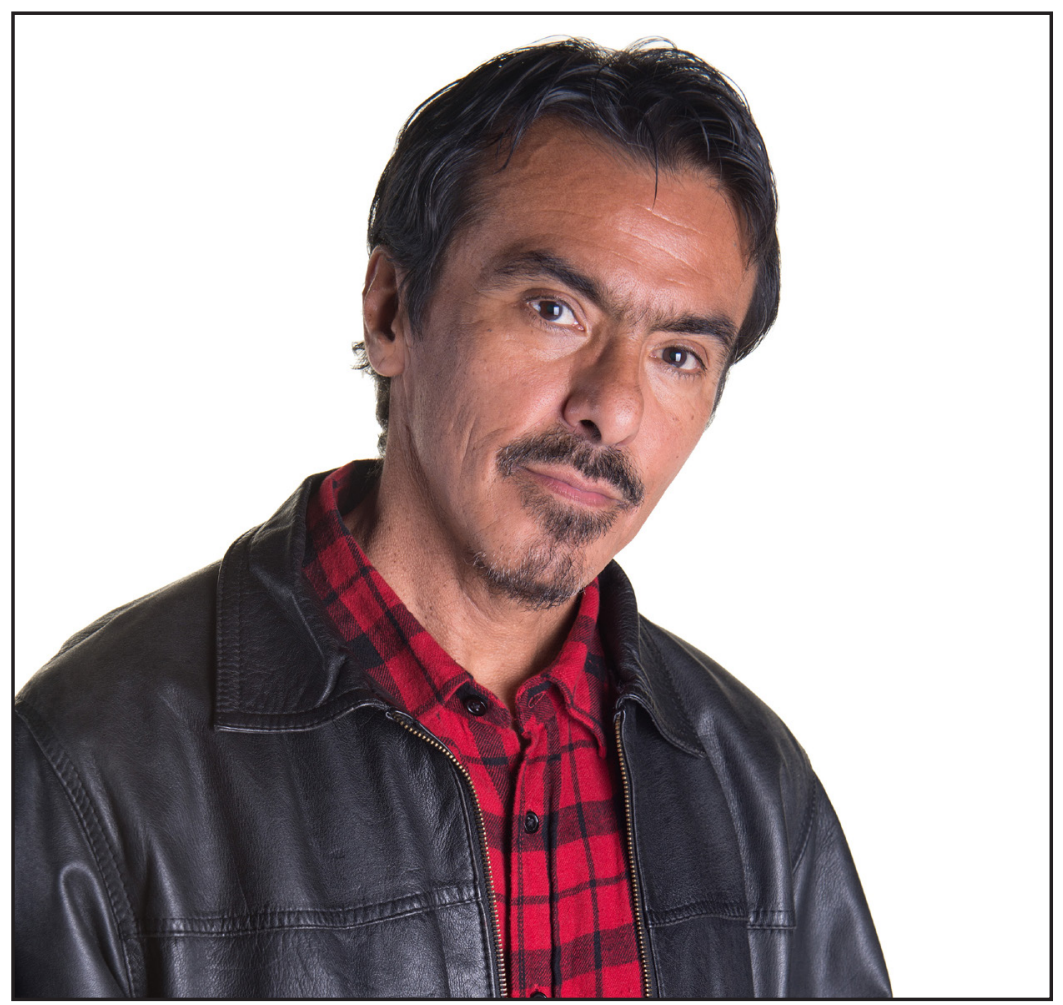

Félix Lozano, actor de la Compañía Titular de Teatro de la Universidad Veracruzana. Archivo de la orTeuv, 2016. Fotografía de Sebastián Kunold.

\section{Querido Félix,}

Ya no viste el estreno de Ojo de perdiz, de la que pudiste haber sido actor. La leímos contigo, ¿te acuerdas?, y en algún momento la pensamos contigo (si vieras qué bien se ve), pero hace apenas unos meses te presentaste a un ensayo de Carballido en su tinta y nos dijiste, con toda discreción, que tenías que tratarte de un problema y que la cosa no pintaba bien. Ésa fue la despedida, o casi, porque todavía diste algunas funciones de Rosalba y los Llaveros; sólo tenías dos apariciones, pero nadie en el público se olvidaba de tu personaje: Erasto, "el aguador".

Un día escuché que querías que alguien te sustituyera porque era muy cansado esperar entre piernas, pero cuando te pregunté si había algún problema no dijiste nada. Yo ni sabía que estabas enfermo. Aquí, en este mismo escenario, dejaste patente dos máximas del teatro: que no hay papel pequeño para el actor y que sólo muerto se falta a una función. Las dos las respetaste hasta el final. Porque no vamos a mentir diciendo que siempre te tocaban los protagónicos, los que conducen anímicamente al espectador; sin embargo, entendías muy bien tu papel en un ensamble que se afina y se modula como un sólo cuerpo. El cuerpo actoral. Pocos lo han entendido como tú. 
Por eso nos resulta tan significativa esta marcha prematura, porque eras parte de nuestro cuerpo, un órgano vital de la orTeuv, la honorable Compañía Titular de Teatro de la Universidad Veracruzana (golpe en el piso y señal al cielo, como solíamos hacerlo), este cuerpo escénico al servicio de los universitarios, los veracruzanos y el arte. Alguna vez te lo dije, que si algo me llamaba la atención de los actores de ORTEuv es que su ego no es individual, sino grupal, nada los enaltece más que el prestigio de su compañía y de la UV.

Estoy convencido de que no es casual que la imagen simbólica de esta definición, la del actor que trabaja por un bien común, la hayas trazado tú en el suelo de la fábrica de San Bruno, en aquellos inolvidables días de El puro lugar. Qué imagen, ¿no?, tú tomando el gis y escribiendo en el suelo: "actor-obrero" u "obrero-actor", según desde donde se leyera.

El actor escondido detrás de la obra, no asomado por delante, como se acostumbra, pero dejando siempre una huella material. Esa obra era como viajar al grado cero de la actuación, ¿no lo pensabas así mientras escribías en el suelo? Sí, me imagino... o tal vez no, lo más extremo para ti fue Psicoembutidos, donde eras un plañidero estafador mostrándose al desnudo por más de dos horas, como todos los demás actores, y a veces hasta algunos espectadores que también se desnudaban. ¿Cómo no iba a ser eso un fenómeno extremo? ¿O la más radical sería Beisbol, donde no sabías lo que te iba a tocar actuar ni a qué hora? Qué curioso, ¿no?, Psicoembutidos y Beisbol fueron hechas espalda con espalda, y mientras en una traías tatuada tu edad en el pecho, en la otra tenías tu nombre en la espalda.

¿Qué curiosa sensación de ser tú mismo y no serlo! Qué curiosa sensación la del actor, que es reconocido por no ser él mismo. ¿Quién eras, Félix? Apenas me doy cuenta que no lo sé. Cada vez que te pongo en la memoria eres el capitán Bedoya de Las muertas, nunca aquel que veía en los pasillos ni en la calle con su bicicleta; de ese Félix conocí muy poco porque te mimetizabas con Xalapa, y pocas veces era dado verte fuera de los teatros. Acaso en las giras a la Ciudad de México, a las Muestras Nacionales, o los viajes a Argentina y a Brasil, donde pudiste echar el resto y sorprenderte con la maravilla de viajar gracias al teatro, allí te vimos sonreír, bailar y echarte muchos tacos de ojo.

Pero en general tu vida estaba en el escenario, en todos los pequeños y grandes personajes, en el Padre Virgilio de Idiotas o en el Vidal Sánchez de El atentado, por no hablar de un Medvedenko en La gaviota que a muchos no nos tocó, pues fue hace 20 años, o aún antes, ¿a quién hacías en Nuestro pueblo? ¿Cuál era tu tarea en Veracruz Veracruz? A veces me pregunto si el público reconocía tu nombre cada vez que lo leía en el programa de mano, pero de lo que no tengo duda es que tu rostro, tu cuerpo y tu voz forman parte de la memoria de emociones de muchos xalapeños. ¿Quién era Félix Lozano? ¿Quién era ése que prestaba su cuerpo a tantos personajes? Eras un actor de la Universidad Veracruzana. Corre video. 